\title{
Why Technological Literacy and for Whom?
}

\section{Dr. John Heywood, Trinity College-Dublin}

John Heywood is professorial Fellow Emeritus of Trinity College Dublin- The University of Dublin. he is a Fellow of ASEE and Life Fellow of IEEE. he has special interest in education for the professions and the role of professions in society. he is author of Engineering Education. research and development in Curriculum and Instruction. 


\section{Why Technological Literacy and for Whom?}

The purpose of this paper is to raise questions about the intent of technological literacy in society at the present time. Unfortunately at an international level there is no clear perception of what technological literacy is whereas in the United States there has been a substantial debate about the need for people to be technologically literate. At the same time there is a tension between those who assume that technological literacy means "learning to compute," and those who believe it is about the relationship of the outputs of computing to society. The response in American engineering higher education seems to have been the teaching of engineering topics to persons not taking engineering. More generally there is interest in courses in "Technology and Society."

Krupczak and other members of the TELPHE Division of the American society for Engineering Education have distinguished between technological literacy and engineering literacy. One approach is to distinguish between the "process" of engineering and its "product" technology. While useful in engineering education at school level and in higher education it is no wonder that the public continue to be confused about the differences between engineering and technology. Krupczak and his colleagues not that "the term engineering is not treated systematically by any of the technological literacy standards which must be to the detriment of engineering, and those wanting to develop engineering standards.

Attempts to show how engineering and technology interact inevitably lead to models that conflate the two literacies and shows them to be embedded in the philosophy that derives them. The model shows no disconnect between the designer and the user; they have joint responsibility for its use.

At the same time these models have been developed without clear reference to the audience for which they are intended. Audiences that are readily identifiable are the general population, the liberal arts undergraduate population, professionals such as lawyers, teachers, medics, and the undergraduate engineering population. The purpose of this study is to provide a limited examination whether there is a community of scholarship that is relevant to every group that is divided by the extent of knowledge and skill required for a particular audience. Recent controversial activities undertaken by General Motors and Volkswagen high light the importance of such an examination. An engineering view of technological literacy is inadequate for the task it is expected to do. An interdisciplinary approach is clearly necessary.

\section{Introduction}

The purpose of this article is to raise questions about the intent of technological literacy in society at the present time. It may be regarded as complementary to, or an extension of the paper defining technological and engineering literacies presented by Krupczak et $\mathrm{al}^{1}$ at the 2012 annual conference of the American Society for Engineering Education, and this writer's response in $2014 .^{2}$

There is no international movement or organization at the political level (e.g OECD) that argues that every person should be technologically and engineering literate. Given the impact of technological change on such diverse things as the workforce and personal values this is surprising. But internationally strong movements have ensured that language, numerical and scientific literacies are well discussed. In consequence there is considerable agreement that students should have minimum competency in the use of their own language (literacy) and basic arithmetic (numeracy). In consequence primary (elementary) and post-primary schools are required to ensure their products are literate and numerate. Politicians compare the relative performance of one country against another on tests that they regard as valid (e.g.PISA).

Arguments have also been made that everyone should have a basic knowledge of science and more recently technology. It is generally assumed that it is the responsibility of the system of schooling to provide for the development of these literacies. In the United States "standards" 
have been adopted for the subjects of the school curriculum including technology. At an international level it is by no means clear what technological literacy is perceived to be or what purpose it is to serve. This is not true of the United States where there has been much discussion as Krupczak et $\mathrm{al}^{1}$ have summarised.

The National Academy of Engineering (NEA) undoubtedly influenced some universities to take technological literacy seriously when it published "Technically Speaking: Why all Americans should know more about Technology" in 2002, and "Changing the Conversation: Messages for Improving the Public Understanding of Engineering" in 2008. Thus in the last decade the American Society for Engineering Education has created a Division for Technological Literacy separate to its division for k-12 education that suggests that technological literacy has a role to play in higher education. In higher education several courses with that intention have been reported. Paper sessions at the ASEE annual conferences have revealed that in the US the minor course might be a useful structure for teaching technological literacy to non-engineers. ${ }^{3}$ There have been a variety of presentations on the teaching of engineering topics to persons not taking engineering. The range of topics offered is illustrated by some of the presentations at the 2013 annual conference shown in exhibit 1.Only one of the presentations came from outside the US, in this case, The University of Buenos Aires. The programme inadvertently highlights one of the dilemmas facing those who would promote technological literacy namely, that it is all too often taken

Application of peer-reviewed journal articles for enhancing technological literacy (Brooks, R.M., Cetin, M., Kavuturu, J and Al-Maghrabi, M-N).

Demonstration of electrical principles in the classroom by hydraulic analogues (Graff, R. W and P. R. Leiffer).

Waves of engineering: using a mini-wave flume to foster engineering literacy (Lyman-Holt, A. L and L. C Ribichaux).

Simulating interest in technological and engineering literacy using multidimensional desktop virtual reality framework (Chandramoudi, M and G. R. Bertoline).

Using heavy metal music to promote technological and socio-cultural understanding (Kirkmeyer, B. P)

Using scale models to promote technological literacy (Loendorf, W.R., Geyer, T. L and D. C. Richeter).

Gadget Avalanche. A technological literacy course for novice adults (Lichini-Colbry, K and D. Colbry).

Information and communications technologies literacy of the University of Buenos Aires engineering students (Clua, $\mathrm{O}$ and M. Feldgen).

Exhibit 1. The title of some of the papers presented at the Technological Literacy Division sessions at the 2013 Annual Conference of the American Society for Engineering Education. A complete session was devoted to problems in the assessment of technological literacy.

by members of the public to mean information technology (IT) combined with artificial intelligence (AI) where IT is taken to mean learning to compute. But, as is well understood, the problems promoted by IT and AI are large and cannot be ignored, particularly as they impact on the professions. ${ }^{4}$ It is nevertheless a basic tension in the promotion of technological literacy, and its relief may be helped by the distinctions that Krupczak et al 
${ }^{1}$ have made between engineering and technological literacy. The need for acceptable distinctions is never more apparent.

\section{Distinctions between engineering and technological literacy}

The distinctions that Krupczak et $\mathrm{al}^{\mathbf{1}}$ found between engineering and technological literacy led the Technological Literacy Division seek to incorporate engineering literacy within in its title. They sought to define by examples the differences between the two (see exhibit 2). One approach offered by Krupczak et al was to distinguish between the two literacies as process and project which is the approach adopted here. Technologies are the products of the process of engineering. If that is in anyway correct, then while useful to engineering educators in school and higher education it is no wonder that the public is confused about the differences between "technologists" and "engineers," and no wonder the media tend to use the term "technologist" more often than they do the term "engineer." The thinking is easy"Technologists make a technology." Worse there is tendency to substitute science and scientists for technology/engineering and technologist/engineer. Krupczack et al reported that "the term engineering is not treated systematically by any of the technological literacy standards" which must surely be to the detriment of the understanding of engineering, as well as its image. Given that this statement includes the ITEEA 2000 Standards it is a matter of considerable consequence for the development of engineering studies in K-12, and supports those who wish to develop standards for engineering literacy.

It would be remiss not to mention the cognate study of "Technology and Society," or the work of institutions such as the European Inter-University Association of Science and Technology, the IEEE Society on the Social Implications of Technology, and the Society for the History of Technology in this area of knowledge which often takes place in schools outside of engineering as for example the departments of philosophy in universities in the Netherlands.

"A person who is technologically literate might have a knowledge of the systems of an automobile such as engine, power train, and brakes along with the basic principles underlying the functioning of these systems. This is knowledge of the product. Engineering literacy would include knowledge or ability to design, analyse or otherwise create the constituent components of the automobile."

"An integrated circuit is a technological device. A person who is technologically literate might be able to describe an integrated circuit, describe what it is, and explain the general uses and importance of integrated circuits. An engineering literate individual would be more familiar with how an integrated circuit can be used as a means of connecting an abstract schematic design into a working physical object."

Exhibit 2. Two of the examples given by Krupczak et al $^{1}$ to illustrate the differences between engineering and technological literacies.

\section{Technological and Engineering Literacy and Liberal Education}

Attempts to show how engineering and technology interact inevitably lead to models that conflate the two literacies. Following an earlier study in which Heywood had argued that engineering was necessarily a component of liberal education ${ }^{2}$ he argued, in a development of Krupczak et als paper, that "the defining characteristic of liberal education was "enlargement of mind. This "enlargement" was achieved by the capacity to perceive inter-relationships between the areas that comprise "universal knowledge" as it is currently understood. It follows that consideration of the "product" (technological literacy) without consideration of 
the "process" (engineering literacy) is not a liberal education." ${ }^{5}$ Using the model he had presented in the earlier paper (exhibit 3) he argued that the solution to engineering problems (the technology) required not only knowledge of engineering science and the mechanics of manufacturing but an understanding of the ways of thinking in such areas as law, management as it embraces the human and social sciences, and philosophy. As such the model conflates the two literacies thereby linking the practical with the theoretical and shows them to be embedded in the philosophy that drives them.

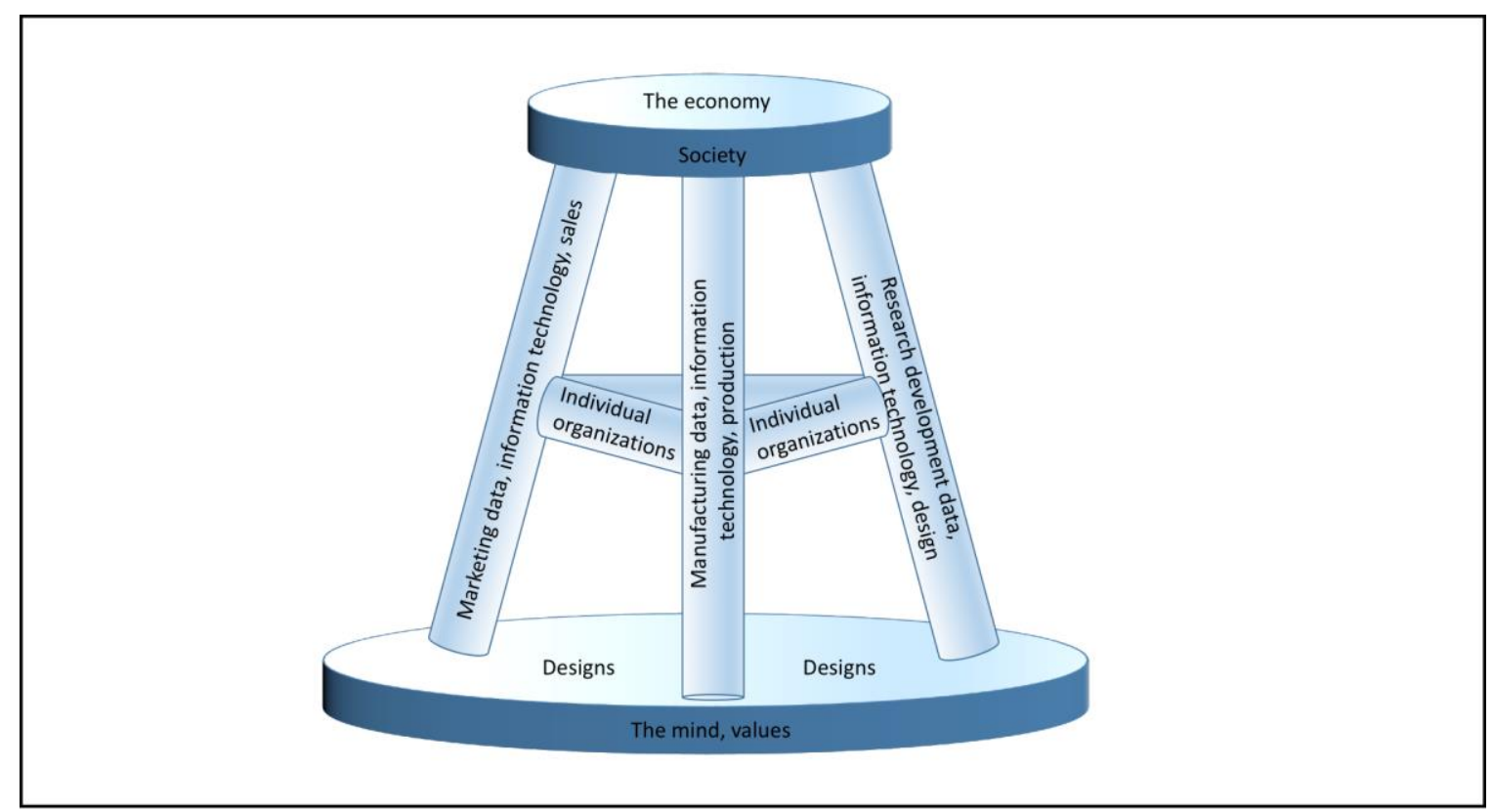

\section{Exhibit 3}

\section{Philosophy, the engineer and the individual}

That thesis and other developments in the philosophy of engineering education led the Division to embrace philosophy in its name at the same time as it introduced engineering literacy into its title. This has confused some members of the Division yet while any study of the process of producing a technology involves engineering it also depends on the values that drive the process as the model shows. There is no escape from philosophy. We all philosophize and we all have personal philosophies, and these drive our actions. The model does not indicate the effect of the socio-economic system on our belief systems although this could be remedied by drawing feedback lines through the legs of the stool from both the seat and the supports.

In the previous paragraphs the concern was with the understanding of what distinguishes technology from engineering - the technologist from the engineer, and with a reconciliation between the two literacies. The point to be added to this discussion is that the model shows no disconnect between the designer and the user (the engineer and the client), they are interdependent and carry a joint responsibility for what and how it is used, and by extension the public; hence the need for the public to be technologically literate. 


\section{The public exercise of responsibility}

While co-responsibility places an obligation on both the designer and the user to consider the ethical implications of a design in action that commitment extends to the public for the simple reason that in most cases there will be many users. This point is illustrated by an editorial in The Times ${ }^{6}$ written in response to the news are now being grown in sheep and pigs. The leader writer wrote "[b]ut the public must be wary of being lulled by technological optimism into forgetting the gravity of the problems raised by these methods. It is entirely legitimate to debate their use. Indeed it would be negligent not to" (see exhibit 4).

There is no point in public discourse unless its intention is public responsibility, the development of which is a major goal of liberal education. "Society itself requires some other contribution from each individual, besides the particular duties of his profession. And, if no such liberal intercourse be established, it is the common failing of human nature, to be engrossed with petty views and interests to underrate the importance of all in which we are not concerned, and to carry our partial notions, into cases where they are inapplicable to act, in short, as so many unconnected units, displacing and repelling one another."7

Since there is a need for ethics to be built into the design then users should be in a position to comment on the design for which they will also need to be engineering literate. This consistent with what Krupczak and his colleagues write about the NAE view of technological literacy was (exhibit 5).

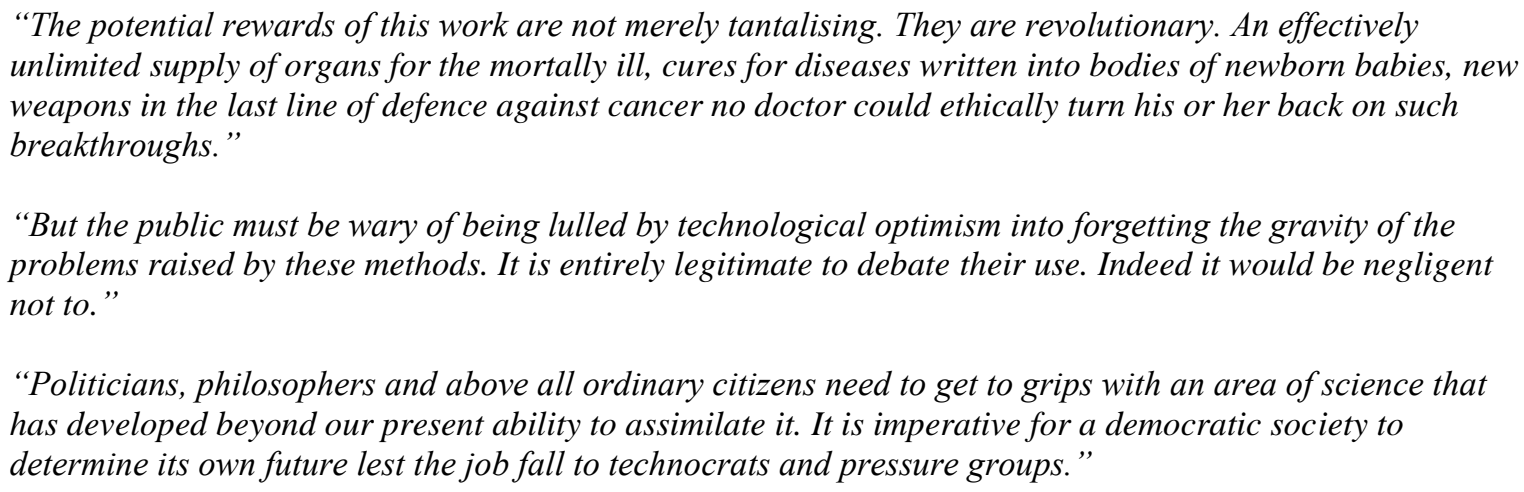

"Politicians, philosophers and above all ordinary citizens need to get to grips with an area of science that has developed beyond our present ability to assimilate it. It is imperative for a democratic society to determine its own future lest the job fall to technocrats and pressure groups."

Exhibit 4. Extract from the $1^{\text {st }}$ Leader "The origin of Species. Human-animal chimeras pose grave questions about the future identity of mankind. All the more reason to press on with the science. The Times, p 21, January $11^{\text {th }} 2016$.

"The NAE promotes technological literacy as a means by which individuals can function more effectively in modern technological society. This is consistent with E. D. Hirsh's general definition of "literacy" as information that is taken for granted in public discourse."

Exhibit 5. Quotation from Krupczak et als paper on "Defining Technological Literacy."1 


\section{The dilemma of the audience and the curriculum}

Of no less importance is the direction which the technocrats of Silicon Valley are taking us. One simple is example is the fact that we have been lulled into giving information to the big social media companies for free which leaves us open to greater control by the powerful.

The implications for the curriculum are profound. A detailed analysis of what these might be is not within the scope of this paper. However, in the light of this discussion it is necessary to focus, if only briefly, on the dilemma created for curriculum designers by the multiple audiences that need some form of technological and engineering literacy. Is there a community of knowledge that can serve these audiences? Or, do they have to be served by multiple pathways because the community of knowledge is so vast? The purpose of this paper is not to delve into the curriculum but to pose the problem in the paragraphs that follow.

It was pointed out that contextual models of the engineering process show that neither, engineering or technological literacy can be properly understood without reference to the other. At the same time these models when related to the curriculum have been developed without clear reference to the audience for which they are intended. Given that there are many possible audiences the content of the curriculum may have to differ considerably as between them. Audiences that are readily identifiable are the general population, the liberal arts undergraduate population, professionals such as lawyers, teachers, medics, and the undergraduate engineering population. The implications for the curriculum are profound. At one extreme, content arises from consideration of the impact of technology on society and individuals in particular. At the other end of the spectrum are the needs of non-engineers who have to deal with engineers and engineering in their everyday activities. Given this scenario it is possible to envisage two (or more) entirely different programs in technological literacy. But there are in addition to dilemmas about content dilemmas about method. This may be illustrated by two recent scandals affecting automobiles-General Motors and Volkswagen.

General Motors had eventually to withdraw 30 million cars worldwide because some ignition switches had failed which had prevented the airbags from inflating. The company paid compensation for 124 deaths. It took a private lawyer from Georgia to pursue the company on behalf of a client to bring to light the problem: a decade passed before the Corporation began to recall call vehicles. ${ }^{8}$ In the case of Volkswagen the US Environmental Protection Agency issued a notification of a violation of the Clean Air Act. ${ }^{9}$ The Agency had found that during official testing, diesel engine vehicles had been programmed to reduce emissions of nitrogen oxide significantly below those emitted during real-road driving. The announcement reverberated around the world and the company had to withdraw millions of vehicles.

In the world of the Web firms that hold a lot of personal data have had to admit that there systems have been attacked.

The question that has to be asked is, "What should a member of the public do about a particular problem, if anything?" In order to answer this question, "What knowledge and cognitive skill does a member of the public have to have to make that decision?" These are quite difficult questions because the only action that a person seems to be able to take is not to buy one or other of these cars. There is little evidence that people will take such action: indeed, at the present time Volkswagen is beginning to restore the volume of sales in the UK. This is a major problem for those who want the public to take the social media industry by 
the neck and seek payment for the information they currently get for free. ${ }^{10}$ These are undoubtedly issues for technological literacy programmes.

\section{Conclusion}

This paper began with a description of developments in technological literacy as seen through the eyes of the Technological Literacy Division of the American Society for Engineering Education prior to 2015 when its name was changed. The focus of conference papers appears to have been on describing courses that enable the understanding of engineering principles. Other papers have been concerned about assessment, and some have discussed the differences between engineering and science. It might be argued that these courses are rather more about engineering literacy than they are about technological literacy. The need to include engineering literacy in the name of the division is supported by Krupczak et al's report on the differences between (meanings of) engineering literacy and technological literacy. ${ }^{1}$ Previous studies of the curriculum were used to support the inclusion of "philosophy" in the title but the notion of philosophy is extended to include the respondent perceived here as the "public." That respondent has as much responsibility for the value system that the engineers have that drive their engineering activities. This has considerable implications for the construction of curricular in technological and engineering literacy. The dilemma for those engaged in technological and engineering literacy is that their curricular have to meet the requirements of many audiences. The difficulty of developing a community of scholarship that meets the needs of all these audiences is illustrated by extreme examples of the questions that the public need to answer in deciding what action they ought to take in response to such happenings as the GM and Volkswagen automobile scandals. An engineering view of technological literacy is inadequate for the task it is expected to do. An interdisciplinary approach is clearly necessary.

\section{References}

[1] Krupczak, J., Blake, J. W., Disney, K. A., Hilgarth, C. O., Libros, R., Mina, M and S. R. Walk (2102). Defining technological literacy, Proceedings Annual Conference of the American Society for Engineering Education. Paper AC 2012-5100.

[2] Heywood, J (2014). Defining engineering and technological literacies within the framework of liberal education: implications for curriculum, Proceedings Annual Conference of the American Society for Engineering Education. Paper 8687.

[3] Krupczak, J., Mina, M., Gustafson, R. J., Young, J. E and S. VanderStroep (2012). Minors as a means of developing technological literacy programs at college level. Proceedings Annual Conference of the American Society for Engineering Education. Paper AC 2012-4696.

[4] Susskind, R and D. Susskind (2015). The Future of the Professions. How Technology will Transform the Work of Human Experts. Oxford, Oxford University Press.

[5] Heywood, J (2010). Engineering literacy: a component of liberal education. Proceedings Annual Conference of the American Society for Engineering Education. Paper AC 2010-1505.

[6] The Times. January $11^{\text {th }} 2016$. Editorial.

[7] Newman, J. H (1852). The Idea of a University. Defined and Illustrated. 1923 Edition. London, Longmans, Green. p 168.

[8] General Motors ignition switch scandal. Wikipedia, the free Encyclopedia. $9^{\text {th }}$ March 2016.

[9] Volkswagen emissions scandal. Wikipedia, the free Encyclopedia. $9^{\text {th }}$ March 2016. 
[10] Lanier, J (2013). Who Owns the Future? London, Allen Lane. 